\title{
Creative Education: A View from Russia
}

\author{
Oleg N. Yanitsky \\ The Federal Center of Theoretical and Applied Sociology of the Russian Academy of Sciences, Moscow, Russia \\ Email: oleg.yanitsky@yandex.ru
}

How to cite this paper: Yanitsky, O. N. (2019). Creative Education: A View from Russia. Creative Education, 10, 752-765. https://doi.org/10.4236/ce.2019.104056

Received: March 21, 2019

Accepted: April 23, 2019

Published: April 26, 2019

Copyright $\odot 2019$ by author(s) and Scientific Research Publishing Inc. This work is licensed under the Creative Commons Attribution International License (CC BY 4.0).

http://creativecommons.org/licenses/by/4.0/

\begin{abstract}
Drawing on the state of affairs in this social institution, the analysis of relevant literature, my professional and family archives and personal experience I came to the following conclusions. First, modern educational system in Russia is built into the structures and requirements of Russian capitalism and its political structure. Second, this educational system relies upon the principles of secondary and higher educational norms and rules shaped in the XX century. Third, the above system follows both the principles of the Enlightenment and an existed structure of branch principle of organization of production and consumer systems, while all they are now highly integrated processes. Fourth, it in turn signifies that the secondary and higher education systems don't fit growing complexities of modern mode of production and ways of life. Fifth, in particular the graduates have no idea about metabolic processes that are permanently going on in all spheres of modern complex systems. The study of metabolic transformations is the best way for adequate comprehension of the world structure and dynamics where we live. Sixth, the key issue of the creative education is the ability of a person to perceive, comprehend, construct and manipulate complex reality as a whole. Seventh, an interdisciplinary approach in all spheres of learning and politics is the cornerstones of creative education. Eighth, the best way of this education is early participation in interdisciplinary research projects and many other complex forms of social activity. Ninth, under current conditions, children and adults have to be permanently educated not only at classes, schools and other institutions-the very process of life is the best teacher. Tenth, the educational process will be truly creative if it will be capable to outstrip a current reality and to be combined with the experiments and constructive activity.
\end{abstract}

\section{Keywords}

Capitalism, Complex Systems, Creative Education, Goods and Beds, Individuals, Information, Interdisciplinary Research, Metabolic Processes, Science, Social Institutions, Teaching 


\section{Sources}

In the present article I've drawn on the scientific publications (not only concerning the education issue) in Russian and foreign books and journals as well as on about 400 in-depth interviews and a set of memoirs of the academics, students, graduate students of those years as well as on my own family archives (see, for example, Yanitsky, 2008, 2012). Describing the modern situation I relied upon my personal studies of transition from the Third to the Fourth scientific and technological revolution that I'd carried out from 1970 onwards. I've studied Russian nature protection movement in which I had used the method of long-term in-depth interviews that had been conducted in the years of 1980s-early 2000s. I see especially valuable the studies of modern childhood across the world conducted by my foreign colleagues (Büchler-Neiderberger, 2010) and the study of children in cities implemented by a group of Canadian researchers (Michelson, 1979, 1979a). As a sociologist, I've also based my studies of the creative education issues in the works of Z. Bauman, U. Beck, M. Castells (1996), S. Kravchenko, S. Sassen, D. Stokols, J. Urry and many others. The seventeen years work in the UNESCO's headquarters and the European Bank of Research and Development gave me valuable experience in theory and practice of education across the world.

\section{Some General Principles of Modern Creative Education}

The very notion "creative" should be explicated and clarified. In principle, all kinds of professions and skills have to be creative ones. But very often the education and first of all the higher education is considered instrumentally i.e. as a precondition to have interesting and well-paid job. This interpretation leads us to a vicious circle: "Education for education itself" without any relation to further job or professional carrier. To my mind, the education in the widest sense of the word represents a teaching of children and adults to be the creators. Therefore, the ultimate goal of a teacher or tutor is to transform the pupils into the creators of their own future.

However, some fundamental questions arise. First, what do we mean under the education as such? Is it upbringing in the kindergartens, and a secondary and a higher education? Or it is an inseparable feature of our life? Second, is an environment in which we live in our teacher as well, or it's something secondary and not important? Third, do the creators is the separate strata of our society, or the creativity is indispensable feature of every person irrespectively of his/her social status and habitat? Fourthly, do a teaching and the Enlightenment are separate social institutions or they are two sides of the same coin? Fifthly, and the most important to me as an urban and environmental sociologist: is the Nature still our main "teacher" or we are all under pressure of complex geopolitical milieu of a cosmic scale? Sixthly, how to combine scientific and technological innovations for a particular branch of industry with social innovations aimed at wellbeing of population and a safety for humanity?

The answer to the first question has been given by Z. Bauman $(2001,2017), \mathrm{U}$. 
Beck (1992), J. Urry $(2003,2008)$ and many others. Since we are living in a permanently changing world we should master new knowledge and crafts throughout our life. That is if the educational institutions as such have to be creative the education processes have to be permanently creative as well. Then, an environment in which we are living is our permanent teacher. That is any creative education has to assists people not only to adapt to changing conditions but to gain them an ability to foresee coming transformations of his/her living environment.

The third question is the most difficult because the creative education of our times has to fulfill two functions: to give way to the most creative minority and simultaneously to disseminate the inventions throughout society preventing social losses and shaping the stratum of the outcasts, or using the Bauman's term, the wasted people. It's not an easy task taking into account the uncertainty and risks of global world the process of transition toward the new scientific and technological revolution (hereafter STR-4). This transition will have a mobilizing character because a majority of resources at hands will be used for geopolitical competition and making the transition period safe as much as possible.

Then, I'm deeply convinced that the teaching and Enlightenment are two sides of the same process. Otherwise, we all will fall either into a techokratismus or into a wishful thinking. Every creative invention has to be morally substantiated and justified.

As for the fifth issue, it seems that nowadays the "nature-society" dichotomy has become totally obsolescent in our integrated worldtied by the networks of the "Internet Galaxy" (Castells, 2004). The notions of a global sociobiotechnical system, metabolic processes and feedbacks within this system are methodologically seem the most relevant for the study of any social phenomena. Besides, for the reason that a time of any innovations and transformations has becoming more and more compressed a life-span of any creative innovation will be compressed as well. In other words, in our times the creative education is an endless process, and each period of it has its own tempo-rhythms.

The answer to the sixth question is still not clear for me. On the one hand, every invention, be it a new medicine or an aircraft, is the integrated result of labor of various scientists, scholars, engineers and many other specialists. Then, a long way to retail and consumers governed by global and national markets begins, and each of them wants to gain maximum profit and public recognition. On the other hand, the institutions and persons at each of the above steps may be creative or formal. Plus a bureaucratic (administrative) machinery that want to get its own share, etc.

\section{Two Sides of the Same Coin}

Let me remind that the very notion of the creativity is Janus-like. From the confessional and philosophical viewpoints there are no an absolute good and absolute evil. And what is about a war and peace? The wars may be predatory and liberation, the hybrid wars is usually difficult to define in moral terms at all. Then, a particular creative act may have very positive immediate results but later on 
the serious negative consequences may appear. The A-bombarding effect of Japanese cities of Hiroshima and Nagasaki had been evaluated positively by some and negatively by many others.

Therefore, it seems necessary to distinguish two kinds of human and institutional creativity: a positive and a negative. But this distinction is rather conditional because they are both tied by a struggle for the resources, the innovations, particular territory, the geopolitical domination, and for many other things. We should recognize that such struggle is unavoidable in particular because the players often switch the places. It means that the creativity isn't an abstract notion it always has the gains for some and the losses for the others.

Then, it's rather indicative that the creative ideas and inventions have usually emerged in the new spheres of scientific, business, engineering and other forms of social activity that later may become a new branch of an industry, politics or mass-media. Therefore, to be the creator doesn't necessarily mean that he or she will invent something absolutely new. Social movement of inventors and rationalizers widely spread among the Soviet Union enterprisers didn't actually invent something extraordinary new but they assisted to modernize, for example, existing machine-tools and other machinery equipment.

\section{Russian Traditions of Creative Education}

On the edge of the XIX and XX centuries Russian university acquired some specific features and traditions. It's going on not about a specificity of these universities as social institutions but an overall social and psychological atmosphere dominated in their academics' and students' communities. These features had been as follows: all-embracing democratic atmosphere, a right of academics and students for self-organization and in some cases a right for self-government. The students' strikes happened here and there: the young demand more democratic principles of university teaching and life. Another significant feature had been an establishment of home circles for students' discussions at any theme which they saw important and interesting. "We want to know much more than it prescribes by teaching programs" had been the motto of such educational activity beyond classes. It means that even in those politically-tense times the students wanted to learn much more and tried to practice multisided approach to current reality beyond the limits of university and national programs.

As outstanding Russian scientists Vladimir Vernadsky wrote in 1911: "the institution of higher education is more than merely as educational institution; in fact, it can only be considered as an institution of higher learning when it goes beyond the limits of the school and serves as a scientific institution, when it functions as an independent center for the nation's scientific thought" (Vernadsky, 1911: p. 179).

Vernadsky repeated many times that the important role of higher education is to reform itself i.e. the creation of new institutions of higher learning and secondary schools of new type. Under this "reform" he meant the teaching of the 
rising generation, to inform that generation about what has been achieved by human thought, and to teach this generation how to think and work creatively. In another article in the same year Russian academics have stated more definitely that Russian intellectual culture in XIX and early XX century has to be considered as a creator of the civic initiatives of academics and students. And this distinguishing feature of university culture is going throughout centuries until now. More detailed description of that period of the life of Russian universities see, in: (Yanitsky, 2008).

\section{From a Pupil to the Social Actor}

As D. Büchler-Neiderberger and her colleagues in 10 countries of all parts of the world clearly showed, it's the all-embracing current trend (see details in: Current Sociology, 2010, 58, No 2), and I may confirm this thesis relying on my own experience as well as on general attitudes of the teaching and education in the Soviet times and later.

It happened that from the childhood I'd been included virtually and really in events in one way or another connected with the mastering of the North way and the North Pole. Despite my age I've been periodically involved in that great enterprise by means of radio, newspapers, adults' talks and the meetings with these heroic expeditions of Soviet scientists, pilots and many others (see details in: Yanitsky, 2012). Of course, it had been the lucky chance. Plus my father had been a geographer who supplied me with the children's books about the process of mastering the world. And my case isn't a single one because in the 1930-40s the Soviet ideologists oriented the youth for being the pathfinders in many directions. It's indicative that the novel "Two captains" about the searches of the missing expedition in the end of XIX century written in the abovementioned period and two movies by this novel are still very popular on Russian TV. It means that a need to do something great is still alive. Even in the school years when the classroom-lesson system dominated the teachers tried to make our worldview as much vide as possible.

\section{On Types and Their Features of the Creativity in Various Situations}

The creativity as a state of a person or group process always includes a mobilization efforts in thinking or doing. That is to be a creator means to be mobilized by a will, idea or a conjecture. It may be said that all creators from Leonardo da Vinci till now had been self-mobilized in one way or another. As U. Beck stated many times there is not totally bed or only good state of matters (Beck, 1992, 1999). Our life as well as a life of natural or socially constructed systems usually represents a combination or interchange of the goods and the bads.

These types and their features depend on a state of affairs in a particular society and in the world as a whole. Very conditionally they may be presented as follows. First, it's the societies that have reached very high living standards and 
attract creative persons across the world. Second, it's the so-called developing countries that have access to main world centers of creative activity. Third, there are many countries which only enter in the period of the STR-3. And fourth, there are countries, regions and even particular cities and communities that are in critical situation.

In this context the term "critical" doesn't necessarily mean the total beds. The majority of critical situations stimulate peoples or communities to search intensively the ways to overcome such situations by means of mobilization of their intellectual potentials and resources at hand. Paradoxically but in the cases of critical situations all gender, social, professional and bureaucratic delimitations are sharply lowering, and a certain integrated creative end-product have emerged. In other words, we are dealing with the process of creative mobilization.

The methods and forms on how to surmount these situations with minimal losses are widely discussed in Russian and foreign sociological literature (Beck, 1992, 1999, 2007, 2015; Bleicher \& Gross, 2010; Dowty \& Allen, 2010; Mol \& Sonnenfeld, 2000; Murphy, 2009; Stokols, 2018; Yanitsky, 2012a, 2012b).

\section{Does Creative Education Is Possible in Transition Period?}

Why the study of such periods is so important? Z. Bauman following A. Gramsci called such period as the interregnum when the existing institutions don't already work for the reason of quickly changing rules of games, and new institutions don't form yet. A global community is now in such situation "in-between", and it aggravates by the fact that natural, social and technical systems are transforming with different tempo-rhythms. Besides, to my mind, the above systems are now existed and developing as a sociobiotechnical whole. Thus, any kind of education including creative one should take into account this new integrated reality.

As to Russia, it went through such interregnum periods at least four times: before and after the set of revolutions in the 1904-17s, the period of intensive industrialization and urbanization in the 1930-40s, the WWII and period of restoration of economy in the 1945-50s, and the times of establishing a capitalist mode of production in early 1990s onwards. Now we are entering in the period of the Four Scientific and Technological Revolution (hereafter STR-4) relied upon information-communication technologies.

Indeed, our society has to make a "triple transit": to renovate its industrial basis, to build new "informational" mode of production and consumption, and to transform its institutional structure. It means that the very term of creativity has a specific connotation to each of the above forms of transit.

As Z. Bauman pointed out, "every generation has its measure of outcasts" because there are people who are ill-prepared to cope with novel challenges', and an intergenerational inequality begin to widened. After "several decades of rising expectations, the present-day newcomers to adult life confront expectations fall- 
ing-and much too steeply and abruptly for any hope of a gentle and safe descent" (Bauman, 2017: p. 3, 4). The reverse side of the same coin is that the creators and realizers of the STR-4 will always be far ahead in comparison with the all the rests but first of all with the outcasts.

Under such uncertain and movable conditions the creative education cannot be the same for all strata of a society i.e. To my mind, the creative education has to be divided on and oriented for the following types of social activity.

First, it has to be simultaneously aimed at two directions: to analyze such activity in the most developed countries in the run of an information-communication industry and to do it as quickly as possible and with minimum human and social losses.

Second, the creative education has to prevent the use of the IT-technology achievements from the enrichment of a minority and impoverishment of a majority of world population.

Third, the creative education has to provide maximum safety of every society from outward interference during the transit processes.

That is why I consider the current transition process may be considered as a specific form of mobilization of creative abilities and resources of our society because each of the above aims is needed in creative approach.

\section{Who Are the "Creative Forces" of Our Society?}

Here some preliminary clarifications are needed. There is a viewpoint that a market is the key creative force. Yes, market is one of universal instruments that stimulate creative activity but as such it's only one instrument among others which stimulate this activity. The market shapes a demand and regulates a balance between the demand and supply. Of course, one may say that a global market is a "producer" of many innovations but it's a viewpoint of aggregated consumer only.

In any transition period from one type of society to another one we need a balance between the innovators whose inventions transform the life of a society and those who adapt the rest of this society to its changes and transformations. This thesis doesn't mean that ordinary people cannot be the inventors. I born in the family of doctors (cardiologists, surgery and pediatricians) and often heard discussion: who is a chief: the diagnostics or ward doctor? To my mind, except some unique scientists like I. Newton or A. Einstein in our times the best "doctor" is a command (team) of a variety of professionals and civic activists which develops an interdisciplinary research project.

More than that, in our highly interdependent society in which all connected with all, at least potentially, it may be concluded that in the global world any creative activity is, in the final analysis, a kind of collective enterprise. Let me remind that besides the global turnover of a matter and energy there is global exchange of innovations and inventions in all spheres of economic, social and political activity. 
Unfortunately, as it very often happened, there is a dark side of such mutual interdependence. I mean that invention of any kind is of a double-edged use. It may be used for war and peace, for construction and destruction, for rising or levelling inequality, etc.

\section{Children in Transition Period}

The matter is that children are the most advanced in computerized society and at the same time is the most vulnerable stratum of transition society. This problem is aggravated by the growing gap between the young and the elderly and this gap is quickly widening in all directions. As Bauman noticed, an "inequality is bad not as such, not because of its own injustice, inhumanity, immorality and life-destroying potential, but for making souls bad and melancholic,... humans become stressed when they find themselves at the bottom of a hierarchy"* (Bauman, 2017: p. 37).

Nevertheless, there are critics of this thesis, because the young and the old feel themselves thrown out from habitual mode of living, and first of all, as a result of shrinking a labor market. But it's not all because the children are nearly full-disoriented, but why?

First, a lot of mechanical and informational playthings may tactile adapt children to some "smart machines" but not to the very complicated and mobile "Internet Galaxy." Besides, these toys are usually very expensive, and the adults have no idea which precisely internet-playthings are the most efficient foe the development of a child creativity. Second, in many Russian kindergartens the majority of the educators have no idea about what such creative development should be. Third, except the tutors in private houses of the reach the parents consider the kindergarten not as a "school of creativity" but as an opportunity to leave their child in a safe place and therefore to have a time for earning money and home work. Fourth, nevertheless, when the child became a schoolchild he already knows much more than he/she acquires in elementary school. Besides, for a long time the child's stay at school has been considered as an institution that offers to a child a definite set of "teaching services" and not as a place for creative development. This situation is especially tense in small provincial towns of the Siberia and the Far East because of the absence of regular connection between these separated settlements and big cities. But paradoxically the children's life in such isolated small settlements is simultaneously much more diverse and integrated. The very mode of living there accustomed children and teenagers to be more self-independent, experienced and creative in several fields. In one way or another, the young armed with a computer and gadget is becoming integrated in the "Internet Galaxy" and its subculture much earlier than the elderly.

\section{The Adults in the Same Period}

In this demographical stratum the ability for creativity is dependent on social status of a production sphere agents. The subject matter of my investigation is a 
mass society and first of all so-called new middle class. His creative potential are usually diminishing replacing by the search of means for adaptation to reducing a labor market, layoffs, dismissals and temporary discharge, and by other forceful measures. This mass of adults except some top managers is usually in a deadlock situation because they are not creators of a digital economy and the "Internet Galaxy." In the universities and research institutions the situation is the same: permanent restructuring, layoffs and dismissals, and lack of funding and the search of the means of survival. Free-lancing and distance work cannot to resolve the problems of the middle class. All in all, the "machine" of institutional reforms of the productive sector lags behind the pace of technological innovations in the digital sphere. Till now, Russian society as many other has no clear and detailed program of transfer to the STR-4.

In a sphere of private life are the same and many other problems. On the one hand, an individual's private sphere is undersiege of hackers' attacks, phone terrorism, the growth of youth gangs and racketeering. On the other hand, it's a growing gap between the attitudes of the young and the old in all and nearly every in each family. An existence of a family as a social institution is the key question. As a result, there are misunderstanding between them and growing mutual alienation.

Besides, the generation of the well trained and experienced elderly is going away, and their professional and life experience isn't fit to the requirements of the digital revolution. It's indicative that this generation of rank-and-file people who has been capable to adapt to transition from state socialist economy to a market one fears the digital revolution. In the Soviet past and in the first years of market economy there were many opportunities for adaptation to new living conditions, say, like a wild market, to survive as profiteers or shift workers. It had been possible to survive using the method of trials and errors. But now they feel that they step on a shaky ground. The old realize that they have no cognitive and vital resources for adapting this quickly developing environment.

There are some possible forms of their "creative education." First and foremost, it is a "return" to rural way of life but with the use of modern (informational) techniques and devises. Russian urban population irrespectively is it a mega-city or small settlement residents usually has a summer house with a plot of land for growing vegetables. It's not a ruralization process-rather it's a mode of combination of rest, calm and self-organized life and a creativity in organizing the rest of his life-span on his/her own way.

In the Soviet times in the period from the 1960s-90s the grassroots activity of the old had been widespread. Each city neighborhood has a group of such activists who made a lot of things: nursing the children and diseased, looking after the flowers, etc. A mutual aid has been very popular. Recently, in the run of all-embracing process of individualization and privatization neighborhood civic activity ceased. The majority prefer internet-communication.

As to travelling of the pensioners widely spread across the world, it exists in 
Russia but not so much. The old Russians usually visited their relatives, grandfathers and grandmothers who live in near or remote provinces.

\section{The Earlier the Better}

At what age such learning process should begin? - As early as possible, because a child is a true creator, an explorer, and this state is usually continues till a kindergarten in which a process of primary socialization begins. Instead of the maintenance of that state by all means a processes of forceful collectivization is launched. A German researcher of the childhood in ten countries clearly showed that recently a child is not an object of any form of manipulation but he/she has become a genuine actor (Büchler-Neiderberger, 2010: pp. 155-163).

Nevertheless, a secondary school in Russia and in many other countries continues to divide his/her interest to an integrated world surrounding them into separate and not interrelated "disciplines" (lessons). Therefore, a teenager could to satisfy his/her interest for creation and construction of various complexities in out-of-school civil organizations (sections, clubs, etc.) only.

Let me give very convincing example. In the Soviet Union and then in Russia from early 1960s till nowadays exists a Student's Nature Protection Movement (in Russian, the Druzhina movement). Why this movement could survive so long, especially in the times of the decay of the USSR and then the hard times of transition from state socialism to wild capitalism? There are at least three preconditions this movement viability. First, after school's class-and-lesson system in the frames of a university there were much more freedom and interpersonal contacts. Second, the Druzhina movement was a kind of brotherhood that had been very attractive because in the secondary school every pupil had been for himself. Third, a degree of variety of contacts grew enormously (academics, students from various faculties, labs, conferences, informal gatherings, etc.). Fourth, the Druzhina had been a very important mechanism for adaptation to urban way of life teenagers from the remote provinces and small towns. Finally, the fifth and most important had been the contacts with a variety of peoples and organizations (scientists, civic activists, local residents, policemen, representatives of local administration and so on). This diversity of contacts and situations are described in the book (Yanitsky, 1993). And the last but not the least, the livability of the Druzhina movement had initially been relied upon its network structure of personal, professional and interdisciplinary contacts.

Let me give an example from my family archive. In the year of 1910 my aunt Vera Schmidt had organized home circle aimed to discuss acute scientific, political and moral issues ranging from "Patterns of Economic Development in General and in Russia in particular" to the "What is the Love, and What are the Factors that Tend to Strengthen or Weaken it." At this meeting on April 19, Vera presented a report titled "Certain Principles of Preschool Education" that contained nine theses: 1) unity of methods of upbringing; 2) harmonious development of the soul and the body; 3 ) general principles of upbringing for boys and 
girls; 4) individualization of upbringing; 5) love for children and the home; 6) the moral authority and personal example; 7) no punishment at all!; 8) respect for the child's personality; and 9) complete mutual trust (archive of Oleg Yanitsky). In 1920s and onwards, Vera Schmidt worked as already being the psychoanalyst and educator. She worked at the children's home "International Solidarity", she prepared the Report "Psychoanalytical Upbringing in the Soviet Russia" (Schmidt, 1927) by the request of Z. Freud and later has been in correspondence with him.

From those times onwards, children's and youth life had been one of the focal point of the state policy and politics. But in the times of perestroika and onwards (1980-early 2000s) the previous forms of this politics like the houses of pioneers had disappeared or focused on the sport. And only recently the state bodies return youth politics on national agenda but still in the form of the "creativity islands."

\section{Bureaucracy as a Barrier for Creative Activity}

A contradiction is very simple: creative persons and groups based on their intellectual and social potential develop various innovations whereas the bureaucracy as asocial institution strives to play a role of mediator between the creators and the users of the goods. Of course, a mediating institution between the creative and bureaucratic groups and institutions is necessary but necessary to fulfill this function of transmitter only. But it's a theory, in reality a system "theory-practice" is needed in many mediating links or sections that convert high-tech theoretical postulates into "information blocks" ready to use by practitioners. Besides, the global market has his particular demands and regulations.

It means that a field for administrative manipulations is potentially open. An administrative apparatus have two sources of resources for its maintenance and expansion: the institute of science-and-education and the users of the end products be it students, teachers, scientists or retailers.

The mechanism of gaining profit is rather simple: to create new and new rules, codes, protocols as well as the accounts, etc. often irrespectively from the needs of the "theory-practice" system exchange. The mechanism of work of this bureaucratic machine well described by M. Burawoy (2008). As it's easy to see, such bureaucratic requirements are now inserted in all documents ranging from an application for getting grant through numerous intermediate steps to final accounts.

The results are as follows. First, the work of such intermediate structure the further the more is slowing down a time of movement from the invention and its experimental testing to the end user. Especially, if one take into account the problems of logistic, transfer from one organization to another and so on. Second, in any case the speed of a particular invention transfer to the end-user has to be quicker than the changes in reality for which a particular device has to be an integral element. If not, it means that the invention become useless. Third, 
for the bureaucracy is profitable the disciplinary barriers and walls because the more disciplines are involved in a particular project the more instructions and decrees bureaucratic machine has to produce, the more staff and funding are needed for its maintenance, and so on. Fourthly, to get a right to regulate the funding of all steps of the process of new knowledge production, dissemination and consumption is a main source of expanding and enrichment of the intermediate institution in question. Actually, the funding of any institution of creativity is the main instrument for domination on it. Fifthly, this rigid administrative system is usually against the various forms of cooperation between the universities, research institutions and civic organizations.

Does all said above mean a deadlock? — Not at all, but the scholars, scientist and practitioners, should step by step to reorganize this system. In principle it's rather simply: to fund it by the final results only. In other words, it's necessary to make this intermediate institution dependent on the R\&D processes, and not as the supervisor of it.

\section{Conclusion}

Any creativity isn't the single act but permanent process combining the accumulation of knowledge and crafts, reflection, and mastering and testing them, inventing something new and testing, and disseminating it into a permanently changing society. That is modern creativity which has to be flexible and mobile as a reality in question. As a rule, the creator has to keep in mind a character and pace of ongoing global transformations which could be linear, nonlinear and unintended ones, gradual and abrupt, etc.

Recently the education as a social institution and a process fulfills two main functions: instrumental and creative. In the process of the coming STR revolution and shrinking of a labor market, the former will be quickly reduced whereas the latter will grow. For those who want to become the true creators a permanent education is the imperative. Such education should implement simultaneously the variety of functions: to be an instrument for successful carrier and self-education, for permanent expanding of individual and group contacts, for travelling, and for cognition of the world as well as of own wills and potentials of a person.

Then, the opposition between the instrumental and creative mode of education provokes a cognitive dissonance between different types of everyday behavior and finally produces two opposing types of human culture: narrow achievable and the Renaissance i.e. universally creative ones. A study of metabolic transformations is a bridge between the above two.

But soon we all will be confronted with absolutely new dilemma: whether people will teach the "smart machines" or they will teach them? It's a purely social question because it means that our society will be divided on those who teach the "smart machines" and those who will teach other people how to live in the "Internet Galaxy." That is, it will be a new form of an old conflict between 
the "creators" and all others.

After then, nevertheless, today an interdisciplinary research project making is the best form of creative education because it combines various forms of human and machine activity: to search relevant information, to combine theory and practice, testing new hypotheses and engineering decisions and therefore stimulating the program equipment development, etc. To be a genuine creator within only one profession is already impossible. It is necessary to combine scientific research, technological knowledge and crafts with civic (public) activism. Today, scientists and scholars shouldn't live in an ivory tower-they have permanently to integrate knowledge, crafts and public activism.

Anyhow, an active participation in the transit from the STR-3 to the STR-4 is the best medicine for revitalization of human creativity irrespectively of their gender, age and social status. The means of such participation are well-known: taking part in political and social discussions, conferences and meetings, participation in social movements including the movements for peace, safety and nature protection, in charity campaigns and movements as well as against inequality and injustice, and many others. The only classroom teaching is insufficient and tedious to the schoolchildren and students. Besides, the genuine creativity is impossible without minimum consent and social solidarity.

In any society there are the leaders of social and technical innovations, especially in transition periods. The problem is how to transfer their results from the islands of creative activity to conversion of this activity into social norms and practices of a society at large.

Finally, we shouldn't forget that an invention of any kind is of a double-edged use. This thesis is equally related to high-tech technologies, mass-media and to everyday life. Genuine creativity is that when it is morally justified and future-oriented. And the study of metabolic transformations and network analysis are the best ways for adequate comprehension of the world where we live and for the forecasting of its future.

\section{Conflicts of Interest}

The author declares no conflicts of interest regarding the publication of this paper.

\section{References}

Bauman, Z. (2001). The Individualized Society. London: Polity.

Bauman, Z. (2017). A Chronicle of Crisis: 2011-2016 (163 p.). London: Social Europe Edition.

Beck, U. (1992). Risk Society. Toward a New Modernity (260 p.). London: SAGE.

Beck, U. (1999). World Risk Society (184 p.). Malden, MA: Polity Press.

Beck, U. (2007). Cosmopolitan Version. Cambridge: Polity Press.

Beck, U. (2015). Emancipatory Catastrophism: What Does It Mean to Climate Change and Risk Society. Current Sociology, 63, 75-77. 
https://doi.org/10.1177/0011392114559951

Bleicher, A., \& Gross, M. (2010). Response and Recovery in the Remediation of Contaminated Land in Eastern Germany. In R. A. Dowty, \& B. L. Allen (Eds.), Dynamics of Disaster. Lessons on Risk, Response and Recovery (pp. 187-202). London, Washington DC: Earthscan.

Burawoy, M. (2008). What Is to Be Done? Theses on the Degradation of Social Existence in a Globalizing World. Current Sociology, 56, 351-359.

https://doi.org/10.1177/0011392107088228

Büchler-Neiderberger, D. (2010). Childhood Sociology-Defining the State of Arts and Ensuring Reflection. Current Sociology, 58, 155-163. https://doi.org/10.1177/0011392109354239

Castells, M. (1996). The Information Age. Economy, Society and Culture. Oxford: Blackwell Publishers, Ltd.

Castells, M. (2004). The Internet Galaxy. Reflections on the Internet, Business, and Society. Oxford: Oxford University Press.

Dowty, R., \& Allen, B. (2010). Dynamics of Disaster. Lessons on Risk, Response and Recovery. London, Washington DC: Earthscan.

Ianitskii (Yanitsky), O. (2008). The Russian University, Professors, and Students in 1910-1915. Russian Education and Society (A Journal of Translations), 70-92.

Michelson, W., Levine, S., \& Michelson, E. (1979a). The Children and the City. Today and Tomorrow (272 p.). Toronto: University of Toronto Press.

Michelson, W., Levine, S., Spins, A.-R. et al. (1979). The Child and the City. Changes and Challenges (520 p.). Toronto: University of Toronto Press.

Mol, A., \& Sonnenfeld, D. (2000). Ecological Modernization around the World: Perspectives and Critical Debates. London: Frank Cass.

Murphy, R. (2009). Leadership in Disaster. Learning for a Future with Global Climate Change. Montreal: McGill-Queen's University Press.

Schmidt, V. (2011). Psychoanalytical Upbringing in the Soviet Russia (76 p.). (in Russian, the First Edition in 1927, in German)

Stokols, D. (2018). Social Ecology in the Digital Age. Solving Complex Problems in a Globalized World(399 p.). Cambridge, MA: Academic Press.

Urry, J. (2003). Global Complexity. Cambridge: Polity Press.

Urry, J. (2008). Mobilities (275 p.). Cambridge: Polity Press.

Vernadsky, V. (1911). The Defeat. In V. Vernadsky (1975). Social and Political Journalism. V. P. Volkov (Ed.). Moscow: Nauka. (In Russian)

Yanitsky, O. (1993). Russian Environmentalism: Leading Figures, Facts, Opinions (226 p.). Moscow: Mezhdunarodnye Otnosheniya Publishing House.

Yanitsky, O. (2008). Training + Research (An Experience of Tutorship). In O. Yanitsky (Ed.), Modernization in Russia: Challenges to Research and Education (pp. 3-12). Moscow: Institute of Sociology.

Yanitsky, O. (2012). The Family Chronicle: 1852-2002 (2nd ed., 272 p.). Moscow: TAUS. (In Russ)

Yanitsky, O. (2012a). From Nature Protection to Politics: The Russian Environmental Movement 1960-2010. Environmental Politics, 21, 922-940.

https://doi.org/10.1080/09644016.2012.724216

Yanitsky, O. (2012b). The 2010 Wildfires in Russia. An Ecosociological Analysis. Sociological Research, 51, 57-75. https://doi.org/10.2753/SOR1061-0154510204 